\section{The management of solitary trichoepithelioma versus basal cell carcinoma}

\begin{abstract}
Currently, all lesions diagnosed clinically as basal cell carcinoma (BCC) are treated by the excision of the lesion with $3-4 \mathrm{~mm}$ margins followed by histopathological examination to assess clearance and confirm the diagnosis. We present the findings of surgical incisional and excisional biopsy of three young patients diagnosed on clinical examination as having $B C C$, who were found on histological examination to have trichoepithelioma. Whilst it may be possible to distinguish the features of trichoepithelioma in incisional biopsy specimens on morphological grounds alone it is often difficult, and immunohistochemical staining, to delineate the features of the basement membrane, provides useful additional information in the histological diagnosis. As trichoepithelioma is more common in the young it should be considered in the differential diagnosis in young patients presenting with BCC-like lesions of the periocular tissues. This subgroup of patients should have incisional biopsy carried out, and if the diagnosis of trichoepithelioma is confirmed the lesion may be excised with a small margin of healthy tissue, thereby facilitating surgical repair.
\end{abstract}

Key words Eyelid, Eyelid tumours, Trichoepithelioma, Basal cell carcinoma, Reconstructive surgery

The distinction between basal cell carcinoma (BCC) and trichoepithelioma is of clinical importance, since conventionally a BCC should be excised with a 3-4 $\mathrm{mm}$ margin of healthy tissue, ${ }^{1}$ whilst trichoepithelioma may only require shave biopsy or minimal resection. ${ }^{2}$ The recurrence rate for trichoepithelioma treated by shave biopsy or minimal resection is low, as is the recurrence rate for trichoepithelioma treated by the non-surgical techniques of argon laser ${ }^{3}$ or cryotherapy. ${ }^{4}$
M. VOTRUBA, C.M.P. COLLINS, R.A. HARRAD
Trichoepithelioma is a benign tumour of the hair follicle $e^{5}$ and is one of a group of follicular tumours. It may be solitary or multiple. ${ }^{6}$

Multiple trichoepithelioma is inherited in an autosomal dominant pattern. ${ }^{7}$ The first lesion often appears in childhood and there are numerous rounded, skin-coloured firm papules measuring 2-8 mm diameter, especially in the nasolabial folds, nose, forehead and upper lip. Solitary trichoepithelioma is more common than multiple and it is not inherited. It is a firm, elevated flesh-coloured nodule less than $2 \mathrm{~cm}$ in diameter and rarely ulcerates. It appears in early adult life, ${ }^{8}$ most commonly on the face.

The histopathology of solitary trichoepithelioma shows a high degree of differentiation towards hair structures and contains numerous horn cysts and abortive primitive hair papillae' (Fig. 1) as well as narrow strands of tumour cells. There is a low mitotic rate and a desmoplastic stroma, with a low quantity of stromal mucin. ${ }^{10}$

$\mathrm{BCC}$ is the most common skin cancer among whites, accounting for $80 \%$ of the 600000 new cases of non-melanoma skin cancer in the USA each year. ${ }^{11}$ It is also the most common skin cancer of the lid, accounting for $80-90 \%$ of cases. ${ }^{12}$ Classically, it occurs in the sun-exposed areas, especially of fair-skinned elderly people. Ninety-five per cent of all BCCs occur in people between 40 and 79 years old, with the average age for BCC of the lid being nearly 60 years; peak incidence occurs in the seventh and eighth decades.

BCC is a slow-growing, shiny, skin-coloured, translucent, raised papule, with telangiectasia on the surface and central ulceration. It has a rolled border and a crusted centre. It is locally invasive and rarely, if ever, metastasises. Two main forms are seen: the rodent ulcer (typically as described above) and the flat, cicatrising morpheaform or sclerosing BCC, whose margins are clinically difficult to delineate.
M. Vortruba, R.A. Harrad Bristol Eye Hospital Lower Maudlin Street Bristol BS1 2LX, UK Tel: +44 (0)117928 4689 Fax: $+44(0) 1179284686$

C.M.P. Collins Department of Pathology Bristol Royal infirmary Bristol, UK 


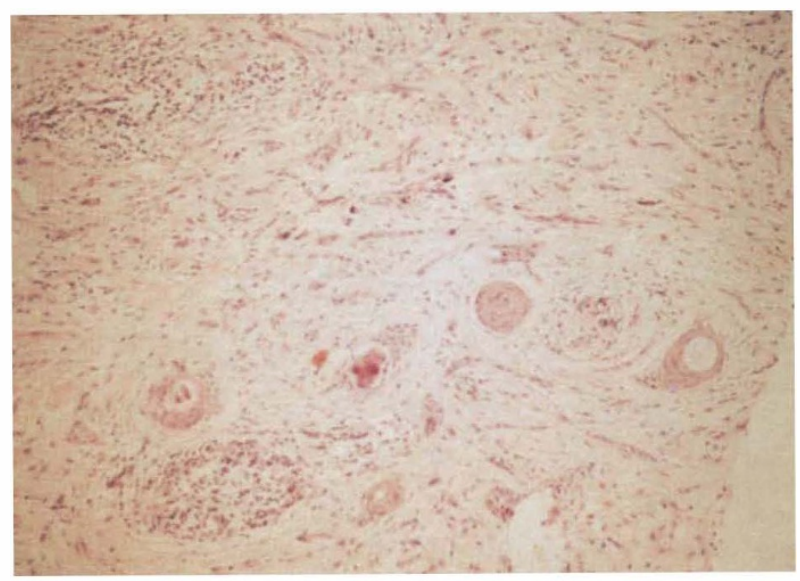

Fig. 1. Trichoepithelioma with horn cysts (HEE, low power).

Histological examination shows masses of compactly arranged basaloid cells, resembling cells in the basal layer of epidermis, with a variable stromal reaction. There is characteristic palisading of dark epithelial cells (Fig. 2). ${ }^{13}$

It can be difficult to distinguish BCC and trichoepithelioma on purely morphological grounds on a small incisional biopsy. Immunohistochemical staining techniques show more clear differences between BCC and trichoepithelioma.

It is thought that BCC spreads by local invasion because it produces a basement membrane - a feature that is largely lost in tumours that exhibit widespread dissemination. The nature of the basement membrane in BCC has been examined by both electron microscopy ${ }^{14,15}$ and immunohistochemical techniques, and the presence of normal basement membrane components including laminin, bullous pemphigoid antigen, collagen IV and collagen $\mathrm{V}$ has been established. ${ }^{16,17}$ Two points arise from the investigation of basement membrane in BCC. Firstly, on ultrastructural examination the basement membrane surrounding a BCC is seen to be discontinuous $^{14,15}$ and, secondly, while in normal epithelial basement membrane proteins are expressed only at the basal pole of the epithelial layer, in BCC there

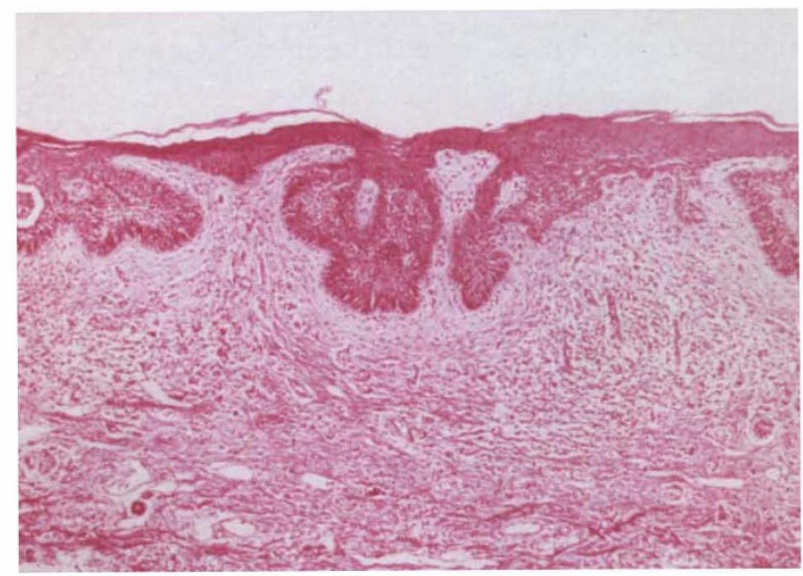

Fig. 2. Basal cell carcinoma showing clear palisading of dark epithelial cells (HEE, low power). is also expression of these proteins as globular deposits within the mass of the tumour, ${ }^{16}$ reflecting, it is thought, the disordered maturation of the cells in BCC.

We have stained our cases of trichoepithelioma and parallel cases of BCC for collagen IV and laminin to demonstrate that differences in expression of the basement membrane proteins in these two tumours may be of help in distinguishing them in small incisional biopsies.

Recent reports ${ }^{18,19}$ have also suggested that staining for bcl-2 and CD34 is useful in differentiating BCC and trichoepithelioma. CD34 is an antigen that stains the spindle-shaped cells in the middle portion of the normal hair follicle. $b c l-2$ is a proto-oncogene associated with programmed cell death. These two stains were also used in our cases.

We report three cases of young adults diagnosed on clinical examination as having atypical BCC who, on histological examination, were found to have trichoepithelioma.

\section{Case reports}

\section{Case 1}

A 32-year-old woman presented with a 2 year history of an elevated, pearly and nodular lump on her right cheek measuring $4.5 \times 5.5 \mathrm{~mm}$ (Fig. 3). It was diagnosed clinically as a BCC. The patient had an excisional biopsy with $3 \mathrm{~mm}$ margins and direct closure of the defect. Histopathological examination showed complete excision of a trichoepithelioma (Fig. 4).

\section{Case 2}

A 43-year-old man presented with a 1 year history of a lesion on the right medial canthus (Fig. 5). It was plaquelike and pearly. A clinical diagnosis of a BCC was made and an incisional biopsy was performed.

Histopathological examination of the small segment suggested a BCC with trichoepitheliomatous differentiation. An excisional biopsy was performed with a clear $4 \mathrm{~mm}$ margin. Further histology showed a trichoepithelioma (Fig. 6). A right glabellar flap reconstruction was performed.

\section{Case 3}

A 32-year-old woman presented with a 1 year history of a left lower lid lump. She was seen in the Accident and Emergency Department where an incision and curettage was performed. The lump was noted to be composed of fibrosed tissue and she was referred for incisional biopsy. The lesion was $15 \mathrm{~mm}$ in diameter, oval, raised, with no central umbo or ulceration (Fig. 7). The central nests of cells were atypical of BCC, suggesting a trichoepithelioma (Fig. 8). Nevertheless, excision with $3 \mathrm{~mm}$ margins was performed. Histopathological examination distinguished the lesion from a sclerosing BCC and confirmed a trichoepithelioma. A Hughes repair was carried out. 


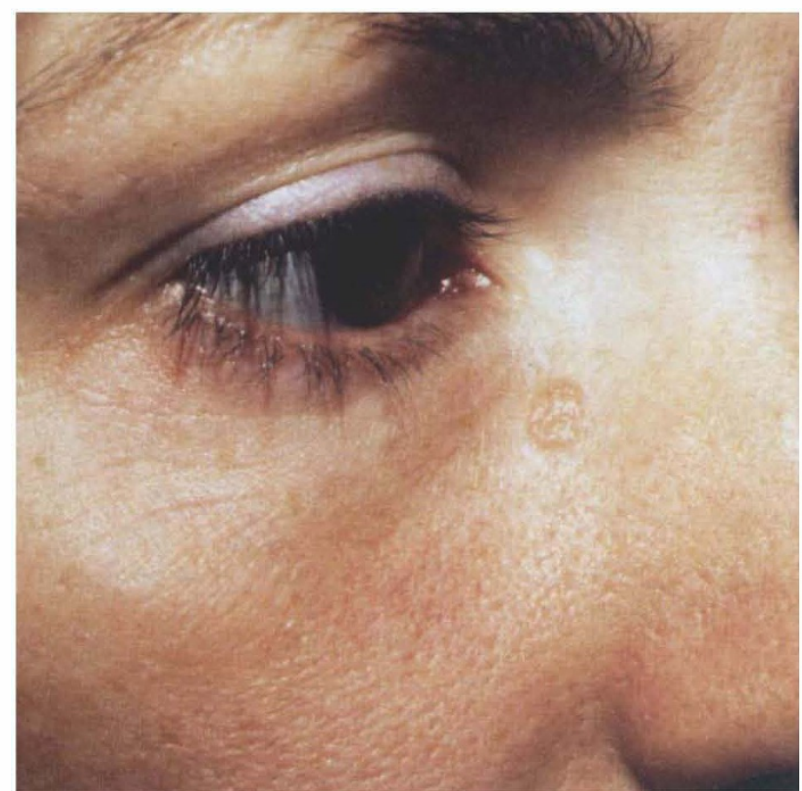

Fig. 3. Case 1 .

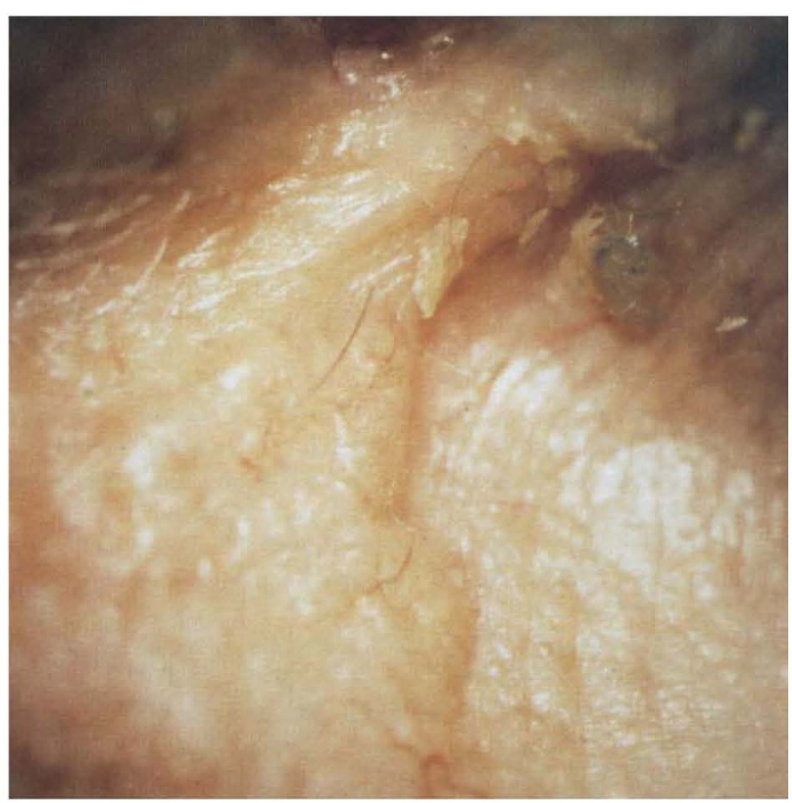

Fig. 5. Case 2.

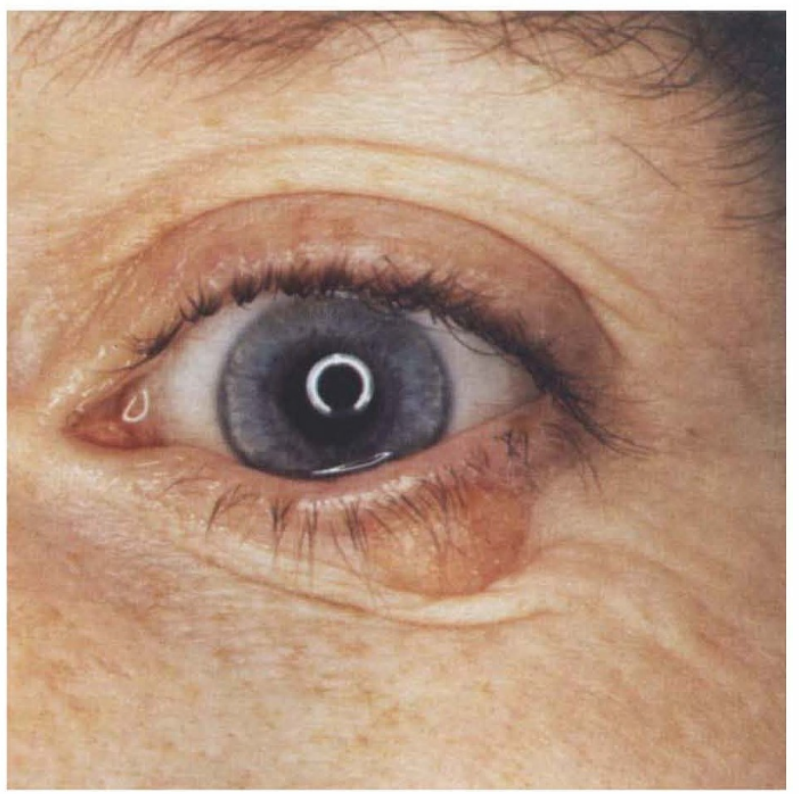

Fig. 7. Case 3.

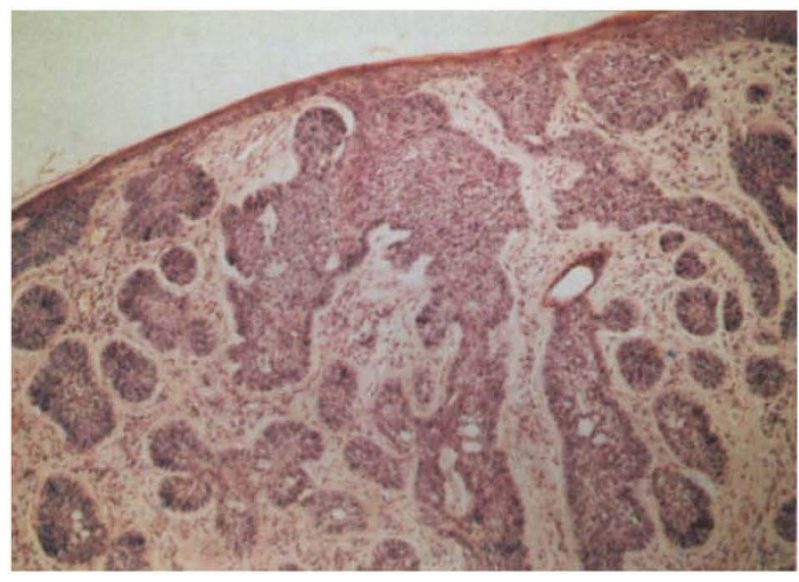

Fig. 4. Case 1. Complete excision of trichoepithelioma showing characteristic horn cysts, primitive hair follicles, low mitotic rate and low quantity of stromal mucin (HEE, low power).

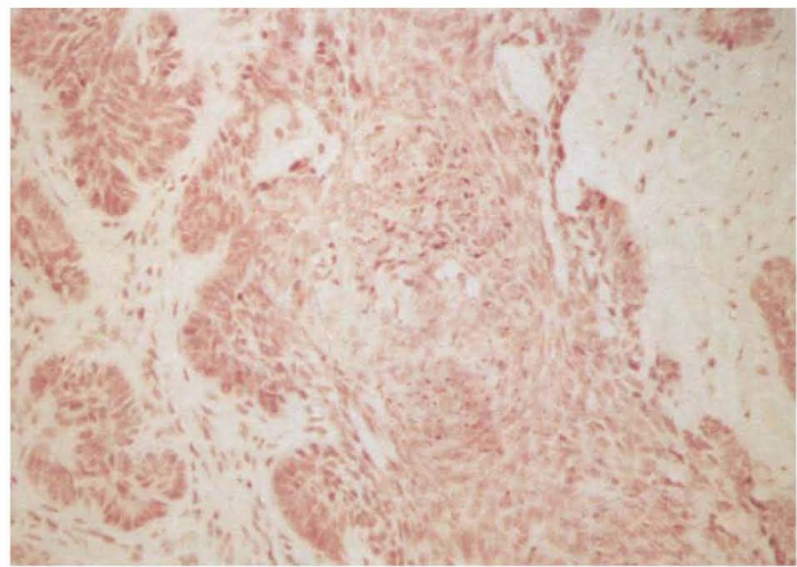

Fig. 6. Case 2. Trichoepithelioma showing keratin formation (HEE, high power).

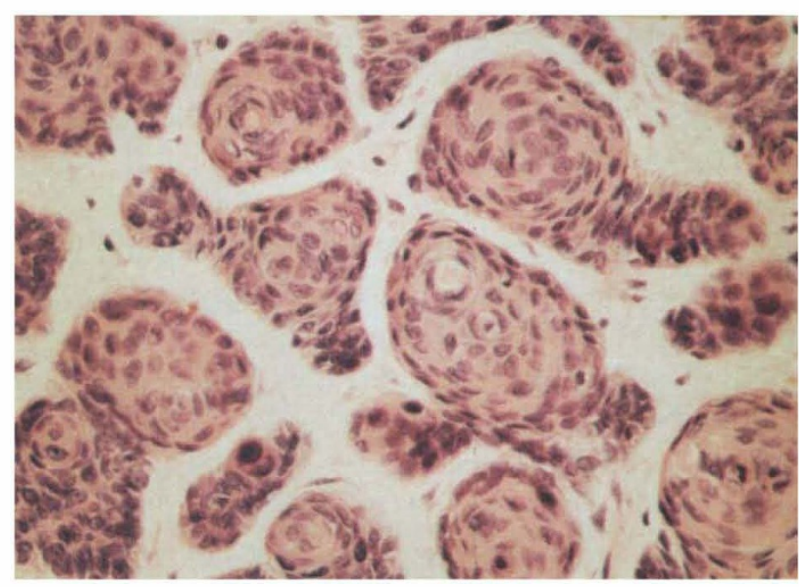

Fig. 8. Case 3. Histology showing central nets of cells with keratin horn cysts (HEE, high power). 


\section{Results}

In our cases of trichoepithelioma we found the expression of a continuous layer of basement membrane, as defined by staining for collagen IV and laminin at the periphery of the tumour lobules, which was essentially indistinguishable from that of normal epithelia. There was no evidence of expression of these proteins within the tumour mass.

In contrast, the expression of collagen IV and laminin in the basement membrane zone of BCC was patchy, discontinuous and ill-defined, and there was evidence of deposition of this protein within the tumour mass. Although the distribution of staining for laminin and collagen IV was similar, laminin stained more weakly and was harder to interpret.

CD34 was strongly positive in our cases of trichoepithelioma but positive only for the blood vessels in the BCC.

Only the outer cells of the trichoepithelioma stained for $b c l-2$, whereas all the cells in the BCC stained positive.

Of the immunohistochemical agents used, collagen IV and CD34 differentiated most clearly between BCC and trichoepithelioma.

\section{Discussion}

Trichoepithelioma, which is a benign lesion, can be removed by shave biopsy or close excision, and surgery need not be as radical as for BCC. ${ }^{2}$ Conventional management of $B C C$ requires excision with a $3-4 \mathrm{~mm}$ margin and histological examination, ${ }^{1}$ or the use of microsurgery with frozen section control (Moh's micrographic surgery) ${ }^{20}$ regardless of subsequent histology. This approach is based on retrospective studies of outcome of excision of all BCCs and does not take into account histological differentiation. Hence, conventional surgical management is based on surgery required for the most aggressive, i.e. morpheaform, tumour. If $\mathrm{BCC}$ recurrence rates were looked at in terms of histological type a smaller excision margin might be adequate in selected cases. In the cases presented the diagnosis of trichoepithelioma was suggested on morphological criteria, but immunohistochemical features, which illustrate the architecture and integrity of the basement membrane in this tumour, provide considerable help in confirming the diagnosis, particularly when only a small biopsy is available. In contrast, the disorganised nature of the basement membrane in BCC is striking and highlights the relatively undifferentiated nature of BCC compared with trichoepithelioma.

Since trichoepithelioma is more common in young people, this diagnosis should be suspected in this subgroup prior to surgery and an incisional biopsy carried out. Excision can then be carried out with a small margin of healthy tissue, facilitating surgical repair.

\section{Conclusion}

Current practice is to treat all lesions clinically diagnosed as BCC in the same way, with excision of the lesion with 3-4 mm margins of healthy tissue. We feel that the diagnosis of trichoepithelioma should be suspected in young patients, and incisional biopsy carried out to confirm the diagnosis, in order to conserve tissue and avoid excessively mutilating surgery.

We thank Mrs G. Bennerson for preparation of the illustrations.

\section{References}

1. Wolf DJ, Zitelli JA. Surgical margins for basal cell carcinoma. Arch Dermatol 1987;123:340-4.

2. Simpson W, Garner A, Collin JR. Benign hair-follicle derived tumours in the differential diagnosis of basal cell carcinoma of the eye-lids: a clinicopathological comparison. $\mathrm{Br} \mathrm{J}$ Ophthalmol 1989;73:347-53

3. Flores JT, Apfelberg DB, Maser MR, Lash $\mathrm{H}$. Trichoepithelioma: successful treatment with argon laser. Plast Reconstr Surg 1984;74:694-8.

4. Duhra P, Paul JC. Cryotherapy for multiple trichoepithelioma. J Dermatol Surg Oncol 1988;14:1413-5.

5. DeVita VT, Hellman S, Rosenberg SA. Cancer: principles and practice of oncology. 4th ed. Philadelphia: JB Lippincott, 1993.

6. Lever WF, Schaunburg-Lever G. Tumours of the epidermal appendages. In: Histopathology of the skin. 7th ed. Philadelphia: JB Lippincott, 1990:578-650.

7. Gaul LE. Heredity of multiple benign cystic epithelioma. Arch Dermatol Syph 1953;68:517-24.

8. Zeligman I. Solitary trichoepithelioma. Arch Dermatol 1960;82:35-40.

9. Takei Y, Fukushiro S, Ackerman AB. Criteria for histologic differentiation of desmoplastic trichoepithelioma (sclerosing epithelial hamartoma) from morphea-like basal cell carcinoma. Am J Dermatopathol 1985;7:207-21.

10. Brownstein $\mathrm{MH}$, Shapiro L. Desmoplastic trichoepithelioma. Cancer 1977;40:2979-86.

11. Boring CC, Squires TS, Tong T. Cancer statistics. Cancer 1992;42:19-38.

12. Lober CW, Fenske NA. Basal cell, squamous cell and sebaceous gland carcinomas of the periorbital region. J Am Acad Dermatol 1991;25:685-90.

13. Brooke JD, Fitzpatrick JE, Golitz LE. Papillary mesenchymal bodies: a histologic finding useful in differentiating trichoepitheliomas from basal cell carcinomas. J Am Acad Dermatol 1989;21:523-8.

14. Koboyasi T. Dermo-epidermal junction in basal cell carcinoma. Acta Derm Venereol 1970;50:40.

15. Hashimoto K, Yamahashi Y, Dabbous MK. Electron microscope observations in vivo and in vitro: collagenolytic activity of the basal cell epithelioma of the skin. Cancer Res 1972;32:2561.

16. Weber L, Krieg T, Muller PK, Kivsch E, Timpl R. Immunofluorescence localisation of type IV collagen and laminin in human skin and its application in junction zone pathology. Br J Dermatol 1982;106:267.

17. Kimura S, Yamasaki Y, Nishikawa S, Hotano H. A comparative study of seborrhoeic keratoses and basal cell epitheliomas by complement immunofluorescence and electron microscopy. Acta Derm Venereol 1980;60:203.

18. Kirchmann TT, Prieto VG, Smoller BR. CD34 staining pattern distinguishes basal cell carcinoma from trichoepithelioma. Arch Dermatol 1994;130:589-92.

19. Smoller BR, van de Rijn M, Lebrun D, Warnke RA. bcl-2 expression reliably distinguishes trichoepitheliomas from basal cell carcinomas. Br J Dermatol 1994;131:28-31.

20. Swanson NA. Moh's surgery: technique, indications, applications and the future. Arch Dermatol 1983;119:761-73. 